\title{
Post-COVID-19 rehabilitation: a special look at chronic kidney disease patients
}

Heitor S. Ribeiro ${ }^{1,2,3^{*}}$ D, Amanda E. Rodrigues ${ }^{4,5}$, Jennifer Cantuária ${ }^{5}$, Antônio Inda-Filho ${ }^{3}$ and Paul N. Bennett ${ }^{6,7}$

\begin{abstract}
Background: Severe acute respiratory syndrome coronavirus 2 (SARS-CoV-2) can infect the kidney and the presence of chronic kidney disease (CKD) constitutes a higher risk of negative prognosis. SARS-CoV-2 main sequelae in CKD patients are an incomplete recovery of kidney function, muscle weakness and atrophy, breathiness, tiredness, pulmonary fibrosis, and initiation of kidney replacement therapy. The overall aim of this review is to provide a theoretical basis for early improvements of physical function health to all CKD stages by rehabilitation therapies.

Conclusion: Chronic kidney disease patients infected with SARS-CoV-2 should be monitored by rehabilitation professionals as the cardiopulmonary, musculoskeletal, and cognitive systems might be deteriorated. Long-term consequences of SARS-CoV-2 are unknown and preventive rehabilitation may attenuate them.
\end{abstract}

Keywords: Exercise, Rehabilitation, Kidney replacement therapy, SARS-CoV-2, Preventive medicine

\section{Kidney as a target of SARS-CoV-2}

Severe acute respiratory syndrome coronavirus 2 (SARSCoV-2) can infect the kidney [33]; however, it is not yet clear if virus replication occurs resulting in functional damage. Given the expression of the angiotensinconverting enzyme 2, the kidney is vulnerable to SARS$\mathrm{CoV}-2$. If kidney dysfunction is caused only by direct damage of the virus or is secondary also to other systemic processes triggered by SARS-CoV-2 it has not been well described. In a cohort of 701 SARS-CoV-2 chronic kidney disease (CKD) patients, the presence of proteinuria and hematuria were associated with an increased risk of in-hospital death up to 11- and 12-fold, respectively [9]. Also, a systematic review and metaanalysis showed that CKD patients were more likely to be transferred to intensive care and undergo mechanical ventilation [17]. Therefore, the presence of CKD on

\footnotetext{
* Correspondence: heitorsiqueira95@gmail.com

'Faculty of Physical Education, University of Brasilia, Campus Universitário Darcy Ribeiro, Brasília, DF ZIP code 70910-900, Brazil

${ }^{2}$ Research Center in Sports Sciences, Health Sciences and Human Development (CIDESD), University Institute of Maia (ISMAI), Porto, Portugal Full list of author information is available at the end of the article
}

admission constitutes a higher risk of a negative prognosis [5].

\section{Main sequelae expected in CKD patients}

Kidney manifestations have been frequently associated with SARS-CoV-2 and unique characteristics in individuals with previous CKD [13]. The prevalence of preexisting CKD is an independent risk factor for acute kidney injury and, followed by hyperkalemia, is the most common kidney complication in the context of coronavirus disease (COVID-19) [12, 24, 43]. As expected, due to its persistent pro-inflammatory state and its functional defects in innate and adaptive immunity, CKD increases the chances of infection in these patients, as well as their development in the most severe forms, and can lead to death [17, 21]. Rhabdomyolysis and metabolic acidosis are also common and are almost always associated with hemodynamic instability [32].

Regardless of whether kidney function is altered on admission or developed during hospitalization, many people experience kidney function loss after hospital discharge [29]. A significant number requires long-term 
follow-up due to incomplete recovery of kidney function, continuous interstitial inflammation, loss of renal vascular cell regenerative potential, and hypertension [21]. The high cost of kidney replacement therapies and the lack of uniform availability of hemodialysis clinics manifest into a challenging scenario. Improving the outcome of these patients is fundamental and emerging; these sequelae cannot become a COVID-19 legacy. For this reason, exercise rehabilitation therapies may play an important role in improving physical function health and attenuating the expected sequels in CKD patients infected by SARS-CoV-2, as seen in Fig. 1.

\section{Cardiopulmonary rehabilitation}

Kidney damage during SARS-CoV-2 infection is a risk factor for CKD development. The COVID-19 survivors, especially those dialysis-dependent or with pre-existing CKD, need to be closely monitored, as they represent a high-risk group [39]. Studies suggest that pulmonary fibrosis will become one of the main sequelae in patients with SARS-CoV-2 infection [6], which may be exacerbated in CKD. Lung damage associated with SARS-CoV2 can lead to the impairment of alveolar air exchange and a decrease of pulmonary ventilation function [25]. As a result, many patients reported respiratory symptoms such as dyspnea and chest tightness, and almost half within 1 month after SARS-CoV-2 infection have developed pulmonary fibrosis, persisting up to 6 months. During hospitalization, the development of cardiac complications such as acute myocardial injury, arrhythmias,

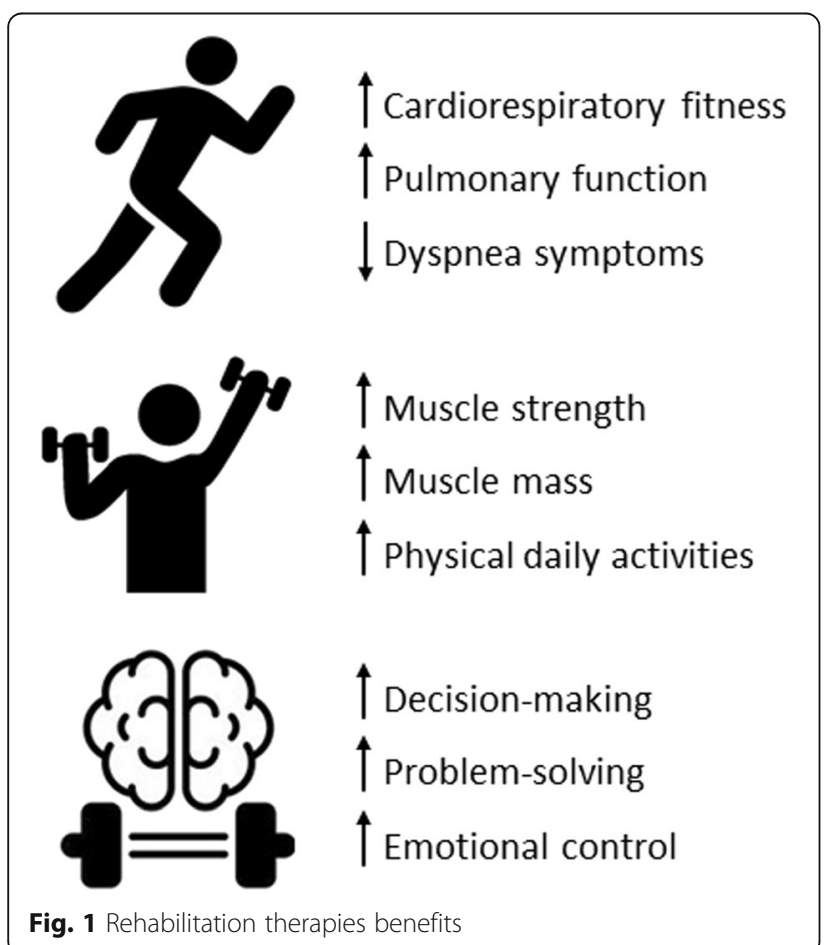

and cardiogenic shock may also be seen, increasing mortality risk in AKI and CKD survivors.

It is known that CKD is associated with the concomitant development of cardiopulmonary diseases, resulting in poor cardiorespiratory fitness and all its deleterious consequences [27]. Lifestyle changes, medication adequacy, health education, and a rehabilitation program with therapeutic exercises can alleviate kidney damage and improve patient outcomes in the long term [2]. The aim of rehabilitation in the context of cardiopulmonary complications of SARS-CoV-2 is to trigger the systemic antioxidant response to modulate the inflammatory state generated by the virus and to intervene in the endothelial dysfunction caused by it. This can be achieved through exercise rehabilitation, among which the most used types are: aerobic, respiratory, resistance, and interval training [7].

Patients with SARS-CoV-2 sequelae are almost always characterized by respiratory problems of varying degrees; for this reason, a cardiopulmonary rehabilitation protocol must be applied and customized based on the specific sequelae of each individual; in this context, the respiratory muscle training has been used as an important tool in the recovery of these patients [11]. Therefore, it is necessary to have an in-depth knowledge of the probable and serious sequelae that surviving CKD patients may develop, as well as the development of action plans to deal with this situation, from the discharge process to the insertion in cardiopulmonary rehabilitation programs.

\section{Musculoskeletal rehabilitation}

SARS-CoV-2 infection can require bed-rest due to fatigue, dyspnea, tiredness, and breathlessness. Moreover, those who needed to be admitted to intensive care units may have been hospitalized for up to 21 days [22]. Long hospitalization periods are associated with muscle dystrophy, systemic inflammation, and musculoskeletal atrophy [4]. It is widely known that CKD patients commonly experience muscle-wasting, muscle weakness, and impaired physical function [35]. Thus, CKD patients affected by SARS-CoV-2 may be at high risk for musculoskeletal health impairments, such as sarcopenia, dynapenia, protein-energy wasting, cachexia, and frailty [34]. Practical approaches to mitigate these possible adverse effects of SARS-CoV-2 in CKD patients' musculoskeletal health should be, therefore, a high priority.

Physical function rehabilitation performed with resistance training, balance exercises, and neuromuscular electrical stimulation could potentially counterbalance muscle and strength losses due to muscle disuse caused by bed-rest and long hospitalization periods [28]. We, therefore, recommend rehabilitation professionals start early interventions in the acute inpatient setting, such as 
passive mobilization, bed mobility, sit-to-stand, and isometric exercises, and for safety reasons, control all clinical parameters [38]. When it comes to hospital discharge, CKD patients infected by SARS-CoV-2 should be continued into physical rehabilitation. Home-based, in-home telehealth, intradialytic, or patient-directed exercises determined to patient needs should be delivered $[3,14]$.

Additionally, supplementation with high-quality protein has been shown to improve physical function and inflammation in CKD patients [41], thus, combined with exercise may play an important role in preserving musculoskeletal health. Considering nutrition and diet holistic aspects of COVID-19 infection, previous studies have already elucidated its importance $[18,31]$.

\section{Cognitive rehabilitation}

The vital interplay between psychological and physical health requires the consideration of cognitive rehabilitation to enhance cardiopulmonary and musculoskeletal rehabilitation. In addition to the somatic symptoms of SARS-CoV-2, quarantine and minimal contact with family and friends can increase fear, stress, and anxiety. This can lead to cognitive deficits related to decision-making, problem-solving, memory, attention, and emotional control [44]. Evidence is emerging highlighting the deficiency in the cognition of SARS-CoV-2 survivors as measured by validated psychological tests such as the Continuous Performance Test [45].

Acknowledging and assessing debilitative cognitive dysfunction in CKD patients is the first step. If cognitive dysfunction is present, cognitive rehabilitation therapy (CRT) may be considered to improve functioning to decrease the debilitating effects of cognitive decline. CRT describes approaches that can restore and enhance cognitive performance and can provide strategies (e.g., mnemonics, memory notebooks) to assist a person with activities of daily living in the presence of cognitive dysfunction [23]. CRT could be performed via telehealth, particularly if face-to-face SARS-CoV-2 restrictions existed [36].
Table 1 summarizes the exercise rehabilitation recommendations for CKD patients for cardiopulmonary, musculoskeletal, and cognitive systems $[1,15,16]$.

\section{Rehabilitation nuances for CKD and general population}

Most of the recent evidence regarding rehabilitation programs for post-COVID-19 survivors is coming from the general population and there is a lack of evidence for CKD, as well as other pre-existing chronic diseases [8, 10, 26]. Daynes et al. [10] showed that a 6-week, twicesupervised rehabilitation program, consisted of aerobic exercise, strength training, and educational discussions improved fatigue, breathlessness, exercise capacity, and cognition. Previously, Liu et al. [26] demonstrated that a 6-week respiratory rehabilitation program was able to improve respiratory function, quality of life, and anxiety in the elderly. Both studies showed no adverse events related to the rehabilitation program and appeared to be safe and effective in improving physical health in general post-COVID-19 survivors.

Based on the limited evidence with the general population, we speculate that the same benefits would be found in CKD patients. Previous studies have shown that CKD patients have worse cardiopulmonary [30], musculoskeletal [37], and cognitive [42] functions than non-CKD subjects. Post-COVID-19 survivors with CKD may have experienced an even worse impact on their physical health than non-CKD. Thus, rehabilitation programs should also be addressed to CKD patients in an attempt to attenuate COVID-19-related sequelae, as previous studies have shown it to be safe and effective in nonCKD. However, there are some specificities related to CKD that need to be addressed and preferable before the commencement of a rehabilitation program in these patients:

- $\mathrm{Kt} / \mathrm{V}>1.2$ (dialysis patients) [20]

- Inter-dialytic weight gain $>4 \mathrm{~kg}$ should be avoided [40]

- Hemoglobin concentration $\geq 13.0 \mathrm{~g} / \mathrm{dL}$ in males and $\geq 12.0 \mathrm{~g} / \mathrm{dL}$ in females [19]

Table 1 Post-COVID-19 rehabilitation recommendations for chronic kidney disease patients

\begin{tabular}{|c|c|c|c|c|}
\hline & Modality & Volume & Intensity & Frequency \\
\hline \multirow[t]{2}{*}{ Cardiopulmonary } & Aerobic exercises & Up to $150 \mathrm{~min} /$ week & $\begin{array}{l}\text { Low to moderate intensity (50- } \\
70 \% \text { HRmax) }\end{array}$ & 3 weekly sessions \\
\hline & Breathing exercises & $\begin{array}{l}3-5 \text { sets of } 10 \text { repetitions/ } \\
\text { day }\end{array}$ & $\begin{array}{l}30 \% \text { of peak inspiratory } \\
\text { pressure }\end{array}$ & 5 weekly sessions \\
\hline Musculoskeletal & Resistance exercises & $\begin{array}{l}8-10 \text { sets of } 12-15 \\
\text { repetitions/week }\end{array}$ & $\begin{array}{l}4-7 \text { at OMNI-RES scale; } 50-70 \% \\
1 \text { RM }\end{array}$ & 2 weekly sessions \\
\hline Cognitive & $\begin{array}{l}\text { Cognitive } \\
\text { Rehabilitation Therapy }\end{array}$ & 15 to $30 \mathrm{~min}$ & Depending on cognitive deficit & $\begin{array}{l}\text { Daily CRT with weekly professional } \\
\text { support via telehealth }\end{array}$ \\
\hline
\end{tabular}

HR heart rate, CRT cognitive rehabilitation therapy, OMNI-RES OMNI resistance training scale, 1RM one repetition maximum 
- Monitor for electrolyte abnormalities (i.e., hypo/ hyperkalemia, hypo/hypercalcemia, hypo/ hypermagnesemia, hypo/hyperphosphatemia) [40]

- Evaluate for pulmonary congestion, pleural effusion, pulmonary hypertension, and/or peripheral edema [40]

\section{Conclusions}

Chronic kidney disease patients affected with SARSCoV-2 should be monitored by rehabilitation professionals as the cardiopulmonary, musculoskeletal, and cognitive systems might be deteriorated due to the infection. During the infection phase, if the patient is physically able to rehab (i.e., not reporting fever or dyspnea, oxygen saturation $\geq 95 \%$, rhythmic heart rate), it should be started respecting all safety procedures to avoid the therapist's infection, but home-based or telehealth sessions should be prioritized. Long-term consequences of SARS-CoV-2 on physical function health are unknown and preventive rehabilitation may attenuate them. Therefore, future experimental studies must be designed to elucidate the rehabilitation benefits of SARS-CoV-2related sequelae in CKD patients from all stages.

\section{Acknowledgements}

We acknowledge all rehabilitation professionals who have been working with us during the COVID-19 pandemic.

\begin{abstract}
Authors' contributions
All authors have contributed equally to the development of this manuscript. HSR has drafted the first version and submitted it. AER and JC have worked with HSR on its development. AIF and PNB have read the final version and approved it. The authors read and approved the final manuscript.
\end{abstract}

\section{Funding}

This review was supported by the Fundação de Apoio à Pesquisa do Distrito Federal (FAPDF) (grant 0193.001.558/2017) and the Pró-Reitoria de Extensão (PROEX) of the University Center ICESP.

\section{Availability of data and materials}

Not applicable.

\section{Declarations}

Ethics approval and consent to participate

Not applicable.

\section{Consent for publication}

Not applicable.

\section{Competing interests}

The authors declare that they have no competing interests.

\section{Author details}

${ }^{1}$ Faculty of Physical Education, University of Brasília, Campus Universitário Darcy Ribeiro, Brasília, DF ZIP code 70910-900, Brazil. ²Research Center in Sports Sciences, Health Sciences and Human Development (CIDESD), University Institute of Maia (ISMAI), Porto, Portugal. 'University Center ICESP, Brasília, Brazil. ${ }^{4}$ Department of Health Sciences, Federal University of Goiás, Goiânia, Brazil. ${ }^{5}$ RenalCare Rehabilitation Center, Goiânia, Brazil. 'Satellite Healthcare, Inc., San Jose, CA, USA. ${ }^{7}$ University of South Australia, Adelaide, Australia.
Received: 16 March 2021 Accepted: 3 June 2021

Published online: 15 June 2021

\section{References}

1. Agostini F, Mangone M, Ruiu P, Paolucci T, Santilli V, Bernetti A. Rehabilitation setting during and after Covid-19: an overview on recommendations. J Rehabil Med. 2021;53(1):jrm00141. https://doi.org/1 0.2340/16501977-2776.

2. Asad A, Burton JO, March DS. Exercise as a therapeutic option for acute kidney injury: mechanisms and considerations for the design of future clinical studies. BMC Nephrol. 2020;21(1):1-11. https://doi.org/10.1186/s12 882-020-02098-9.

3. Barker-Davies RM, O'Sullivan O, Senaratne KPP, Baker P, Cranley M, DharmDatta S, et al. The Stanford Hall consensus statement for post-COVID-19 rehabilitation. Br J Sports Med. 2020;54(16):949-59. https://doi.org/10.1136/ bjsports-2020-102596.

4. Brower RG. Consequences of bed rest. Crit Care Med. 2009;37(10):S422-8. https://doi.org/10.1097/CCM.0b013e3181b6e30a.

5. Bruchfeld A. The COVID-19 pandemic: consequences for nephrology. Nat Rev Nephrol. 2021;17(2):81-2. https://doi.org/10.1038/s41581-020-00381-4.

6. Cacau LDAP, Mesquita R, Furlanetto KC, Borges DLS, Forgiarini Junior LA, Maldaner $\mathrm{V}$, et al. Evaluation and intervention for cardiopulmonary rehabilitation of COVID-19 recovered patients. ASSOBRAFIR Ciência. 2020; 11(Supl1):183-93. https://doi.org/10.47066/2177-9333.AC20.covid19.018.

7. Calabrese M, Garofano M, Palumbo R, Di Pietro P, Izzo C, Damato A, et al. Exercise training and cardiac rehabilitation in COVID-19 patients with cardiovascular complications: state of art. Life. 2021;11(3):259. https://doi. org/10.3390/life11030259.

8. Ceravolo MG, Arienti C, de Sire A, Andrenelli E, Negrini F, Lazzarini SG, et al. Rehabilitation and COVID-19: the Cochrane rehabilitation 2020 rapid living systematic review. Eur J Phys Rehabil Med. 2020;56(5):642-51. https://doi. org/10.23736/S1973-9087.20.06501-6.

9. Cheng $Y$, Luo R, Wang $K$, Zhang M, Wang Z, Dong $L$, et al. Kidney disease is associated with in-hospital death of patients with COVID-19. Kidney Int. 2020;97(5):829-38. https://doi.org/10.1016/jkint.2020.03.005.

10. Daynes E, Gerlis C, Chaplin E, Gardiner N, Singh SJ. Early experiences of rehabilitation for individuals post-COVID to improve fatigue, breathlessness exercise capacity and cognition - a cohort study. Chron Respir Dis. 2021;18: 1-4. https://doi.org/10.1177/14799731211015691.

11. Ferreira B, Tozato C, Vitelli Molinari C, Papa V, Guizilini S, Ferreira V, et al. Cardiopulmonary rehabilitation in COVID-19. Revista Da Sociedade de Cardiologia Do Estado de São Paulo. 2020;30(4):531-6. https://doi.org/10.293 81/0103-8559/20203004531-6.

12. Flythe JE, Assimon MM, Tugman MJ, Chang EH, Gupta S, Shah J, et al. Characteristics and outcomes of individuals with pre-existing kidney disease and COVID-19 admitted to intensive care units in the United States. Am J Kidney Dis. 2021;77(2):190-203.e1. https://doi.org/10.1053/j.ajkd.2020.09.003.

13. Gansevoort RT, Hilbrands LB. CKD is a key risk factor for COVID-19 mortality. Nat Rev Nephrol. 2020;16(12):705-6. https://doi.org/10.1038/s41581-02000349-4.

14. Gentil P, de Lira CAB, Coswig V, Barroso WKS, de Oliveira Vitorino PV, Ramirez-Campillo $R$, et al. Practical recommendations relevant to the use of resistance training for COVID-19 survivors. Front Physiol. 2021;12(March):111. https://doi.org/10.3389/fphys.2021.637590.

15. Grossman GB, Sellera CAC, Hossri CAC, Carreira LTF, Avanza AC, de Albuquerque PF, et al. Position statement of the Brazilian Society of Cardiology department of exercise testing, sports exercise, nuclear cardiology, and cardiovascular rehabilitation on activities within its scope of practice during the covid-19 pandemic. Arq Bras Cardiol. 2020;115(2):28491. https://doi.org/10.36660/abc.20200797.

16. Gutenbrunner C, Stokes E, Dreinhöfer K, Monsbakken J, Clarke S, Côté $P$, et al. Why rehabilitation must have priority during and after the COVID-19pandemic: a position statement of the Global Rehabilitation Alliance. J Rehabil Med. 2020. https://doi.org/10.2340/16501977-2713.

17. Henry BM, Lippi G. Chronic kidney disease is associated with severe coronavirus disease 2019 (COVID-19) infection. Int Urol Nephrol. 2020;52(6): 1193-4. https://doi.org/10.1007/s11255-020-02451-9.

18. Kalantar-Zadeh K, Moore LW. Impact of nutrition and diet on COVID-19 infection and implications for kidney health and kidney disease management. J Ren Nutr. 2020;30(3):179-81. https://doi.org/10.1053/j.jrn.202 0.03.006. 
19. KDIGO. KDIGO clinical practice guideline for anemia in chronic kidney disease. Kidney Int Suppl. 2012;2(4):282-335. https://doi.org/10.1038/kisup.2 012.40 .

20. $\mathrm{KDOQI}$. KDOQI clinical practice guideline for hemodialysis adequacy: 2015 update. Am J Kidney Dis. 2015;66(5):884-930. https://doi.org/10.1053/j.ajkd.2 015.07.015.

21. Khoshdel-Rad N, Zahmatkesh E, Shpichka A, Timashev P, Vosough M. Outbreak of chronic renal failure: will this be a delayed heritage of COVID19? J Nephrol. 2021;34(1):3-5. https://doi.org/10.1007/s40620-020-00851-9.

22. Kiekens C, Boldrini P, Andreoli A, Avesani R, Gamna F, Grandi M, et al. Rehabilitation and respiratory management in the acute and early postacute phase "instant paper from the field" on rehabilitation answers to the COVID-19 emergency. Eur J Phys Rehabil Med. 2020;56(3):323-6. https://doi. org/10.23736/S1973-9087.20.06305-4.

23. Koehler R, Wilhelm E, Shoulson I. Cognitive rehabilitation therapy for rraumatic brain injury: evaluating the evidence: National Academies Press:; 2012. https://doi.org/10.17226/13220.

24. Kunutsor SK, Laukkanen JA. Renal complications in COVID-19: a systematic review and meta-analysis. Ann Med. 2020;52(7):1-9. https://doi.org/10.1080/ 07853890.2020.1790643.

25. Li J. Rehabilitation management of patients with COVID-19: Lessons learned from the first experience in China. Eur J Phys Rehabil Med. 2020;56(3):335-8. https://doi.org/10.23736/S1973-9087.20.06292-9.

26. Liu K, Zhang W, Yang Y, Zhang J, Li Y, Chen Y. Respiratory rehabilitation in elderly patients with COVID-19: a randomized controlled study. Complement Ther Clin Pract. 2020;39(May):101166. https://doi.org/10.1016/j. ctcp.2020.101166.

27. Martens CR, Kirkman DL, Edwards DG. The vascular endothelium in chronic kidney disease: a novel target for aerobic exercise. Exerc Sport Sci Rev. 2016; 44(1):12-9. https://doi.org/10.1249/JES.0000000000000065.

28. Moro T, Paoli A. When COVID-19 affects muscle: effects of quarantine in older adults. Eur J Translat Myology. 2020;30(2):219-22. https://doi.org/10.4 081/ejtm.2020.9069.

29. Nugent J, Aklilu A, Yamamoto Y, Simonov M, Li F, Biswas A, et al. Assessment of acute kidney injury and longitudinal kidney function after hospital discharge among patients with and without COVID-19. JAMA Netw Open. 2021;4(3):e211095. https://doi.org/10.1001/jamanetworkopen.2021.1 095.

30. Painter P, Messer-Rehak D, Hanson P, Zimmerman S, Glass NR. Exercise capacity in hemodialysis, CAPD, and renal transplant patients. Nephron. 1986;42(1):47-51. https://doi.org/10.1159/000183632.

31. Pérez-Torres A, Caverni Muñoz A, Lou Arnal LM, Sanz Paris A, Vidal Peracho C, la Torre Catalá J, et al. Multidisciplinary nutritional consensus on assessment and nutritional dietary treatment in patients with chronic kidney disease and SARS-CoV-2 infection. Nefrología, In Press. 2021. https:// doi.org/10.1016/j.nefro.2020.12.009.

32. Portolés J, Marques M, López-Sánchez $P$, de Valdenebro M, Muñez E, Serrano ML, et al. Chronic kidney disease and acute kidney injury in the COVID-19 Spanish outbreak. Nephrol Dial Transplant. 2020;35(8):1353-61. https://doi.org/10.1093/ndt/gfaa189.

33. Puelles VG, Lütgehetmann M, Lindenmeyer MT, Sperhake JP, Wong MN, Allweiss $L$, et al. Multiorgan and renal tropism of SARS-CoV-2. N Engl J Med. 2020:383(6):590-2. https://doi.org/10.1056/NEJMc2011400.

34. Ribeiro HS, Wilund KR, Lima RM. COVID-19 quarantine in chronic kidney disease patients: a focus on sarcopenia traits. Bras J Nefrol In Press. 2021. https://doi.org/10.1590/2175-8239-jbn-2020-0201.

35. Sabatino A, Cuppari L, Stenvinkel P, Lindholm B, Avesani CM. Sarcopenia in chronic kidney disease: what have we learned so far? J Nephrol. 2020: 0123456789. https://doi.org/10.1007/s40620-020-00840-y.

36. Sakai T, Hoshino C, Yamaguchi R, Hirao M, Nakahara R, Okawa A. Remote rehabilitation for patients with COVID-19. J Rehabil Med. 2020;52(9):1-8. https://doi.org/10.2340/16501977-2731.

37. Segura-Ortí E, Gordon PL, Doyle JW, Johansen KL. Correlates of physical functioning and performance across the spectrum of kidney function. Clin Nurs Res. 2018;27(5):579-96. https://doi.org/10.1177/1054773816689282.

38. Sheehy LM. Considerations for postacute rehabilitation for survivors of COVID-19. J Med Internet Res. 2020;22(5):1-8. https://doi.org/10.2196/19462.

39. Silver SA, Adu D, Agarwal S, Gupta KL, Lewington AJP, Pannu N, et al. Strategies to enhance rehabilitation after acute kidney injury in the developing world. Kidney International Reports. 2017;2(4):579-93. https:// doi.org/10.1016/j.ekir.2017.04.005.
40. Smart NA, Williams AD, Levinger I, Selig S, Howden E, Coombes JS, et al. Exercise \& Sports Science Australia (ESSA) position statement on exercise and chronic kidney disease. J Sci Med Sport. 2013;16(5):406-11. https://doi. org/10.1016/j.jsams.2013.01.005

41. Tomayko EJ, Kistler BM, Fitschen PJ, Wilund KR. Intradialytic protein supplementation reduces inflammation and improves physical function in maintenance hemodialysis patients. J Ren Nutr. 2015;25(3):276-83. https:// doi.org/10.1053/j.jrn.2014.10.005.

42. Viggiano D, Wagner CA, Martino G, Nedergaard M, Zoccali C, Unwin R, et al. Mechanisms of cognitive dysfunction in CKD. Nat Rev Nephrol. 2020;16(8): 452-69. https://doi.org/10.1038/s41581-020-0266-9.

43. Xiao G, Hu H, Wu F, Sha T, Zeng Z, Huang Q, et al. Acute kidney injury in patients hospitalized with COVID-19 in Wuhan, China: a single-center retrospective observational study. J Southern Med Univ. 2021;41(2):157-63. https://doi.org/10.12122/j.issn.1673-4254.2021.02.01.

44. Zarrabian S, Hassani-Abharian P. COVID-19 pandemic and the importance of cognitive rehabilitation. Basic Clin Neurosci J. 2020;11(April):129-32. https:// doi.org/10.32598/bcn.11.covid19.194.5.

45. Zhou H, Lu S, Chen J, Wei N, Wang D, Lyu H, et al. The landscape of cognitive function in recovered COVID-19 patients. J Psychiatr Res. 2020; 129(Oct):98-102. https://doi.org/10.1016/j.jpsychires.2020.06.022.

\section{Publisher's Note}

Springer Nature remains neutral with regard to jurisdictional claims in published maps and institutional affiliations.
Ready to submit your research? Choose BMC and benefit from:

- fast, convenient online submission

- thorough peer review by experienced researchers in your field

- rapid publication on acceptance

- support for research data, including large and complex data types

- gold Open Access which fosters wider collaboration and increased citations

- maximum visibility for your research: over $100 \mathrm{M}$ website views per year

At $\mathrm{BMC}$, research is always in progress.

Learn more biomedcentral.com/submissions 